fit to practise' are fair and valid. These difficult judgements must involve more than counting courses attended and hours spent listening to lectures. We believe isolation and insight are readily understandable to our profession and able to be stated in operational terms and we offer them as two pillars upon which these judgements could be based.

\section{Stephen J Cox and John D Holden}

\section{REFERENCES}

1. GMC. Revalidation. http://www.gmcuk.org/about/reform/Revalidation.asp (accessed 1 Jun 2009).

2. RCGP. Good medical practice for general practitioners. Maintaining good medical practice. http://www.rcgp.org.uk/PDF/Corp_GMP06.pdf accessed 15 Jun 2009).

3. RCGP. Good medical practice for general practitioners. http://www.rcgp.org.uk/pdf/PDS_Good_Medical_Practic e_for_GPs_July_2008.pdf

4. Cox SJ, Holden JD. Presentation and outcome of clinical poor performance in one health district over a 5 -year period: 2002-2007. Br J Gen Pract 2009: 59; 344-348.

5. National Clinical Assessment Service. Analysis of the first four years' referral data. London: NCAS, 2006.

6. Kay M, Mitchell GK, Clavarino AM, Doust J. Doctors as patients: a systematic review of doctors' health access and the barriers they experience. Br J Gen Pract 2008; 58: 501-508.

7. Howard, JC. Small Groups in Mersey region 1989-1998. Educ for Gen Pract 2001; 12: 47-57.

8. Anonymous. Federations in action: the St Helens experience. RCGP News 2009; Jan: 8 .

9. Hippisley-Cox J, Pringle M, Coupland C, et al. Do single handed practices offer poorer care? Cross sectional survey of processes and outcomes. BMJ 2001; 323: 320-323.

10. Pringle M. The Shipman Inquiry: implications for the public's trust in doctors. Br J Gen Pract 2000; 50: 355-356.

11. McKinstry B, Peacock H, Shaw J. GP experiences of partner and external peer appraisal: a qualitative study. $\mathrm{Br}$ J Gen Pract 2005; 55: 539-543.

12. Lublin JR. Role modelling: a case study in genera practice. Med Educ 1992; 26: 116-122.

13. GMC. Licensing and revalidation. http://www.gmcuk.org/register/licensing/index.aspuk.org/register/licensin g/index.asp (accessed 1 Jun 2009).

14. BMA. Board of Medical Education. Exploring Mentoring. http://www.academicmedicine.ac.uk/uploads/BMA\%20 mentoring.pdf (accessed 12 Jun 2009).

15. Cox J, King J, Hutchinson A, McAvoy P. Understanding Doctor's performance. Oxford: Radcliffe Publishing, 2006.

16. Holden J. Systematic review of published multi-practice audits from British general practice. I Eval Clin Pract 2004; 10: 247-272.

17. Reason J. Beyond the organisational accident: the need for "error wisdom" on the frontline. Qual Saf Health Care 2004; 13 (Suppl 2): ii28-ii33.

18. Medical Schools Council. The role of the doctor: past, present and future. A celebration of 150 years of the Medical Act. Consensus statement. http://www.chms.ac.uk/RoleoftheDoctor2008.htm (accessed 1 Jun 2009).

19. NICE. Response to the report of the Bristol Royal Infirmary Inquiry.

http://www.nice.org.uk/niceMedia/pdf/bristolreportrespo nsefinal.pdf (accessed 1 Jun 2009).

DOI: 10.3399/bigp09X453675

\title{
Reflections in a cracked mirror
}

How I hate the modern obsession with reflection.

After every talk and lecture, at almost every trainers and appraisers meeting for the last few years and in everything associated with the medical learning industry, I am encouraged to reflect. To reflect on what I have learned and to shine that secondhand light on how my new knowledge will change the way I practise.

There are now Structured Reflective Templates as part of our annual appraisals. A contradiction in terms if ever there was one.

I have been a doctor for a third of a century. Seeing, thinking, absorbing, accommodating, and altering the way I work. Daily, hourly, constantly. I see what makes sense, what works better and I automatically adapt. Without thinking.

After all, isn't that what professionals do?

Usually this is a natural and subliminal process without recourse to protected time, a formal thought pattern or that selfconscious, unnecessary, and artificial selfanalysis of reflection. We don't need to be told to do the obvious.

It works like this: someone with more experience tells you what works for them and you try it out yourself next time an appropriate situation arises. Thus, it has always been.

Or you do something that doesn't work and you don't do it that way again. In life as in medicine.

But for the last 5 to 10 years we have been encouraged to reflect on new information and how it will change us. This is like a photographer delaying the taking of a picture long enough to analyse why he is taking that particular picture. Or wondering how that picture will influence the viewer once he has taken it, rather than being spontaneous, instinctive, natural.

But it is worse than that. It isn't just that the whole process of being asked to reflect is artificial pointless and patronising; reflection isn't even a correct use of the word.
I mean, if they can get the concept so wrong, how can we trust anything they ask us to do?

You see the problem is this: reflecting is what mirrors and burnished surfaces do. They bounce incoming energy, that is, light, off their surfaces. The light doesn't penetrate their smooth skins and in the process the light is turned upside down. They are blissfully unaffected by it. Lateral inversion, left to right, back to front.

So reflection is a process whereby the reflector is uninfluenced by the reflecting, the incoming energy is turned upside down and reality is distorted.

So next time you are asked to reflect on a piece of information or an experience just bear in mind the fact that doing so won't change you. The moment you start you will instantly get it all back to front and, anyway, isn't it faintly narcissistic to keep reflecting like that?

Surely if we are talking about the physics of processing energy, what we should be doing is diffracting or refracting.

You see, these are processes whereby a prism or other penetrable transparent surface separates and defines the important constituents of incoming light, changes it, interprets it in a new way and helps clarify its secrets.

It is an even more appropriate term when you find out that the refractive index is related to the denseness of the medium.

Also the process is often startlingly pretty and always a pleasant surprise.

Now diffusion: that is something completely different.

\section{Chris Heath}

DOI: 10.3399/bjgp09X453684 